Lennart van Zellem

Corinne Buysse

Marlous Madderom

Jeroen S. Legerstee

Femke Aarsen

Dick Tibboel

Elisabeth M. Utens

\section{Long-term neuropsychological outcomes in children and adolescents after cardiac arrest}

Received: 27 December 2014

Accepted: 30 March 2015

Published online: 18 April 2015

(C) The Author(s) 2015. This article is published with open access at Springerlink.com

Take-home message: Long-term neuropsychological assessment of CA survivors showed significant weaknesses, but also relatively intact functioning. As deficits in intelligence, memory and executive functioning have significant impact on the child, long-term follow-up and neuropsychological support of CA survivors is warranted.

Electronic supplementary material The online version of this article (doi: 10.1007/s00134-015-3789-y) contains supplementary material, which is available to authorized users.

L. van Zellem · C. Buysse ( $)$. M. Madderom - F. Aarsen - D. Tibboel Intensive Care and Department of Pediatric Surgery, Erasmus MC-Sophia Children's Hospital, Wytemaweg 80, 3015 CN Rotterdam, The Netherlands e-mail: c.buysse@erasmusmc.nl

M. Madderom - J. S. Legerstee · F. Aarsen - E. M. Utens Department of Child and Adolescent Psychiatry/Psychology, Erasmus MC-
Sophia Children's Hospital, Rotterdam, The Netherlands

n

Abstract Purpose: Research into neuropsychological functioning of survivors of cardiac arrest (CA) in childhood is scarce. We sought to assess long-term neuropsychological functioning in children and adolescents surviving CA.

Methods: Neuropsychological follow-up study involving all consecutive children surviving CA between January 2002 and December 2011. Intelligence (IQ), language, attention, memory, visual-spatial, and executive functioning were assessed with internationally validated, neuropsychological tests and questionnaires. Scores were compared with Dutch normative data. Results: Of 107 eligible children, 47 who visited the outpatient clinic (median follow-up interval: 5.6 years) were analyzed. Fifty-five percent had an in-hospital CA, $86 \%$ a non-shockable rhythm, and $49 \%$ a respiratory-related etiology. CA survivors scored significantly worse on full-scale IQ $(\bar{x}=87.3)$, verbal IQ $(\bar{x}=92.7)$, performance IQ $(\bar{x}=85.6)$, verbal comprehension index $(\bar{x}=93.4)$, perceptual organization index $(\bar{x}=83.8)$, and processing speed index $(\bar{x}=91.1)$, than the norm population (mean $\mathrm{IQ}=100)$. On neuropsychological tests, compared with norms, respectively adjusted for IQ, significantly worse scores were found on visual memory, significantly better on verbal memory (recognition), and comparable outcomes on visual-motor integration, attention, other measures of verbal memory, and executive functioning. On

questionnaires, parents reported better executive functioning than the norm, but teachers reported more problems in planning/organizing skills. Conclusions: Long-term neuropsychological assessment of CA survivors showed significant weaknesses, but also relatively intact functioning. As deficits in IQ, memory and executive functioning have significant impact on the child, long-term follow-up and neuropsychological support of CA survivors is warranted.

Keywords Heart arrest .

Follow-up studies .

Neuropsychology · Pediatric ·

Cognition 


\section{Introduction}

Survival after cardiac arrest (CA) in children is low and dependent on the location of the arrest [1]. In-hospital (IH) CAs are associated with relatively high survival rates of 30-50 and 60-90\% have a generally good neurologic outcome $[1,2]$. Out-of-hospital $(\mathrm{OH}) \mathrm{CAs}$ generally have a low survival rate of $10 \%$ and high morbidity rates $(>90 \%)[1,3]$. Long-term prognosis in survivors seems to be associated with location, age, rhythm, witnessing of the arrest and Pediatric Cerebral Performance Category (PCPC) score at discharge [4]. Until now, a detailed overview of the long-term neuropsychological consequences is lacking.

Neuropsychological functioning refers to, e.g., memory, language, attention, and executive functioning. Executive functioning refers to several higher-order and interrelated cognitive functions (e.g., cognitive flexibility, task initiation, planning, working memory, self-regulation, and response inhibition). Considering the adverse impact of a lack of oxygen to the brain, neuropsychological deficits are to be expected. Problems with attention, executive functioning and deficits in visualmotor integration have been reported in children with complex congenital heart disease and survivors of meningococcal septic shock [5, 6]. Also, in neonates with severe respiratory failure treated with ECMO, deficits in attention and behavior were found [7].

Only three small studies and one case report have investigated the neuropsychological functioning of children who survived a CA. Maryniak et al. [8] found visual and verbal memory impairments 6 months after the arrhythmic CA ( $n=10$; mean age 15.7 years). Amicuzi et al. [9] reported a detailed long-term case study of a 9-year-old girl recovering from an anoxic encephalopathy after CA and reported dysfunctions in gnosis, praxis and self-regulation. Morris et al. [10] reported lower scores on tests measuring intelligence, visual-perceptual-motor, achievement, and adaptive functioning in CA survivors at least 1 -year post-CA $(n=25$; mean age 67 months; median follow-up interval unknown; $80 \%$ had a congenital heart disease). Suominen et al. [11] found impairments in intelligence, verbal and/or visual memory, and executive functions in resuscitated drowned children ( $n=21$; median age 12.5 years; median follow-up interval 8.5 years). However, these studies had methodological limitations (small sample size, short follow-up interval or only subgroups of CA studied). It is therefore unknown whether these results can be generalized to all CA survivors.

We sought to systematically investigate the long-term neuropsychological outcomes and predictors of those outcomes in a relatively large cohort of consecutive survivors of $\mathrm{CA}$ in childhood. We used internationally validated, well-known neuropsychological assessment instruments.

We hypothesized that survivors of CA in childhood have significant impairments in neuropsychological outcome.

\section{Methods}

This study was performed at the intensive care unit (ICU) of the Erasmus MC-Sophia Children's Hospital in Rotterdam, the only university specialized pediatric ICU in this region with approximately 4.2 million inhabitants, representative of the Dutch population.

The Erasmus MC Ethical Review Board approved the study protocol (NL 39084.078.12) in accordance with Dutch laws and regulations, and international conventions, such as the Declaration of Helsinki.

\section{Patient sample}

This study concerned all consecutive surviving patients aged $0-18$ years with CA between January 2002 and December 2011, admitted to the ICU of the Erasmus MCSophia Children's Hospital.

CA was defined as absent pulse rate or the need for cardiac compressions. Treatment of children with CA in our hospital was in line with the European Resuscitation Council guidelines for pediatric life support.

All CA data were retrospectively collected from ambulance registration forms, clinical and electronic medical records, and CA registration forms. We collected: (1) basic patient characteristics (e.g., gender, age, medical history), (2) CA characteristics [e.g., type of resuscitation (BLS/APLS), etiology of arrest, first monitored rhythm, bystander CPR, location], and (3) outcome (mortality).

Eligible for this study were children resuscitated: (1) in-hospital (e.g., emergency department, ward, ICU), (2) in a regional hospital or other university hospital, and after return of spontaneous circulation (ROSC) subsequently admitted to our ICU, and (3) out-of-hospital, and subsequently admitted to our ICU. Neonates resuscitated at the hospital's neonatal intensive care unit (NICU), or in another hospital and subsequently admitted to the NICU of our hospital, were excluded.

Procedure: informed consent was obtained from parents, and children (if $\geq 12$ years). In May 2013, participating children (and parents) were invited for an extensive neuropsychological examination, in-hospital, by a pediatric psychologist (MM), 2-11 years after ICUdischarge. 
Neuropsychological functioning

Intelligence tests and neuropsychological tests

Dutch versions of the intelligence tests and neuropsychological tests were used to assess the variables below:

1. Intellectual functioning: the age-appropriate versions of the Wechsler Scales (WPPSI-III, WISC-III, WAISIV) [12-14].

2. Language: Peabody picture vocabulary test -3 th edition (PPVT-III) [15].

3. (Verbal) memory: Rey's auditory verbal learning test (RAVLT) [16, 17]; Rey-Osterrieth Complex Figure test (ROCF) [18].

4. Visual-spatial functioning: Rey-Osterrieth complex figure test (ROCF) [18]; Beery developmental test of visual motor integration-5th edition (Beery VMI-5th edition) [19].

5. Attention: test of everyday attention for children (TEA-Ch) [20].

6. Executive functions: stroop color word test (Stroop) [21]; trail-making test (TMT) [22].

Scores on neuropsychological tests were compared with normative data from representative Dutch general population samples, for corresponding age categories (see Supplementary Table 1).

\section{Neuropsychological questionnaire}

Behaviour rating inventory of executive function questionnaires [BRIEF; parent version (5-18 years), teacher version (5-12 years), and self-report version (12-18 years)] [23].

\section{Putative predictors}

The following predictors were tested: age at time of CA and follow-up, gender, type of CPR (BLS/APLS), location (in-hospital/out-of-hospital), CA-related pre-existing medical condition, participation in a standardized multidisciplinary follow-up program, and socioeconomic status (SES) at follow-up. In our hospital, a multi-disciplinary follow-up program for children with congenital anatomical malformations and children treated with ECMO was started as standard of care in 1999. SES at time of follow-up was based on parents' occupation, and categorized as "low" (elementary occupations), "middle" ("middle' occupations), or "high" ("highest' scientific occupations) conforming to Dutch classification [24]. The highest occupation of both parents was used.
Statistical analyses

Patient and CA characteristics of participants and nonparticipants were examined with independent sample $t$ tests for normally distributed continuous data, and Mann-Whitney $U$ tests for non-normally distributed data. Normality of all data was examined with the Kolmogorov-Smirnov test. Fisher's exact test was used for comparison of dichotomous data.

One-sample statistical tests were performed to compare CA survivors with normative data regarding the BRIEF and intelligence. One-sample $t$ test was performed for normally distributed data ( $t$ scores presented; means of the normative data presented in Supplementary Table 1), or one-sample Wilcoxon signed rank test for non-normally distributed data. Data of the neuropsychological assessment were compared with normative data, corrected for age, gender, or intelligence. In order to compare the performances of all children, scores were converted into $Z$ scores. These $Z$ scores were compared with the $Z$ score of the overall performance of CA-children on full-scale intelligence, as this reflects the overall capacity of the functioning of CA survivors; children with a lower IQ will have a lower neuropsychological functioning. To compare this neuropsychological outcome of CA survivors with normative data, the one-sample $t$ test was performed for normally distributed data, or the one-sample Wilcoxon signed rank test for non-normally distributed data.

Predictors of neuropsychological outcomes were examined with Spearman correlations for continuous variables (age at time of CA, age at follow-up), MannWhitney $U$ test for dichotomous variables (gender, location, BLS/APLS, CA-related pre-existing condition, participation in a follow-up program), and the KruskalWallis test for ordinal variables (SES).

All analyses were performed with SPSS 21.0 for Windows (SPSS, Chicago, IL, USA). Statistical significance was considered with 2-tailed $p$ values of $<0.05$.

\section{Results}

Our target population consisted of 145 surviving patients, 38 of whom were deceased or lost to follow-up (Fig. 1). Causes of death after hospital discharge were another CA without ROSC $(n=3)$, underlying disease $(n=2)$, severe cerebral damage $(n=1)$, or unknown $(n=7)$.

Of 107 eligible patients, $47(44 \%)$ participated. Median follow-up interval was 5.6 years (range 1.8-11.9). Intellectual functioning of one patient was recently tested $(<1$ year) and therefore not repeated at our hospital. His test results were used in this study. Twelve of 47 patients participated in the multidisciplinary follow-up program. 


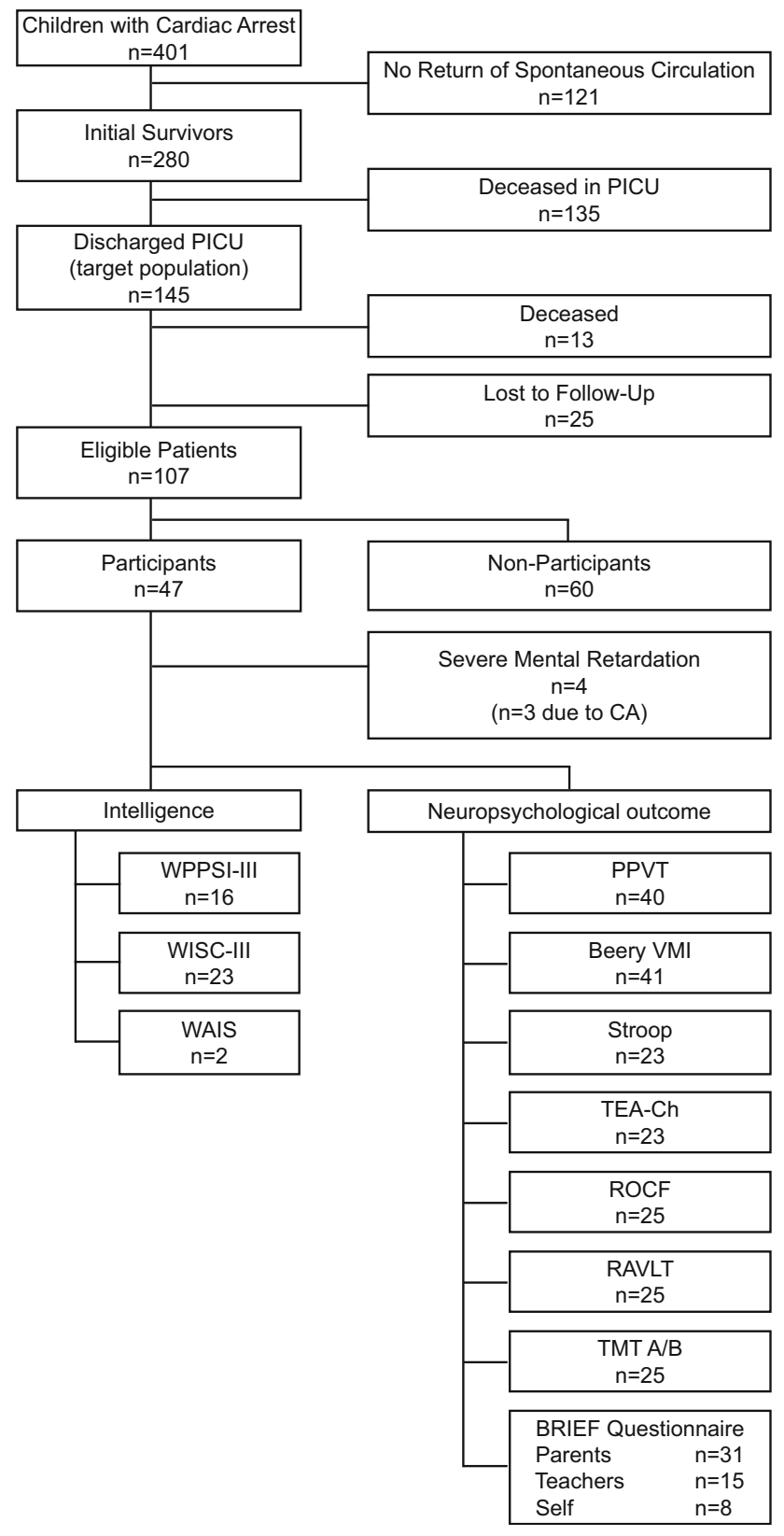

Fig. 1 Flowchart of patient inclusion. Lost to follow-up: moved abroad $n=7$, untraceable $n=18 . n$ is the actual number of children tested, or the number of respondents to the questionnaire (BRIEF). Numbers of patients may differ for neuropsychological tests due to different age ranges covered by the different tests (and availability of norm data). Beery VMI Beery developmental test of visual motor integration, BRIEF Behaviour rating inventory of executive function questionnaires, $P I C U$ pediatric intensive care unit, $P P V T$ peabody picture vocabulary test, $R A V L T$ Rey's auditory verbal learning test, $R O C F$ Rey-Osterrieth complex figure test, Stroop stroop color word test, TEA-Ch test of everyday attention for children, TMT trail making test, WAIS Wechsler adult intelligence scale, WISC Wechsler intelligence scale for children, WPPSI Wechsler preschool and primary scale of intelligence
Four participants could not be tested due to severe mental retardation ( $n=3$ due to $\mathrm{CA}$ ).

Non-participants refused participation due to practical reasons ( $n=23$, e.g., distance to hospital/work of parents), or emotional reasons ( $n=16$, e.g., too anxious/confronting). For 21 non-participants, the reasons were unknown.

Medical characteristics of participants and non-participants were compared, and differed significantly on high SES (Table 1).

Neuropsychological functioning

Intelligence tests

CA survivors scored significantly worse on full-scale IQ (87.3, $t=-6.01)$, verbal IQ $(92.7, t=-3.32)$, performance IQ (85.6, $t=-7.07)$, verbal comprehension index (93.4, $t=-2.26)$, perceptual organization index $(83.8$, $t=-5.81)$, and processing speed index (91.1, $t=-3.16$ ), than the normal population (Table 2).

\section{Neuropsychological tests}

After adjustment for (taking into account) their intellectual functioning (mean IQ $Z$ score: -0.84), CA survivors performed significantly better on receptive vocabulary (PPVT), attentional switching (TEA-Ch attentional switching), and verbal memory recognition (RAVLT recognition) (Figs. 2, 3; Table 2). Significantly worse scores were found on short- and long-term visual-spatial memory (Rey immediate and delayed recall). No significant differences were found on visual-motor integration, attention, verbal memory (RAVLT 1-5, delayed recall), and executive functions.

\section{Questionnaire}

Parents reported significantly better functioning on the executive composite score and behavior regulation index, and subtests organization of materials, and monitoring (Table 3; Supplementary Table 3). Teachers reported better scores on subtest inhibition, but worse on subtest planning/organizing compared to normative data. On selfreports, no significant differences were found.

\section{Predictors of outcome}

Males scored significantly worse than females on performance IQ $(Z=-2.522, p=0.012)$, visual-motor integration $(Z=-1.999, p=0.046)$, selective attention 
Table 1 Characteristics of participants and non-participants

\begin{tabular}{|c|c|c|c|c|c|}
\hline \multirow{3}{*}{$\overline{\text { Age at cardiac arrest (years) }}$} & \multicolumn{2}{|c|}{ Participants $(n=47)$} & \multicolumn{2}{|c|}{ Non-participants $(n=60)$} & \multirow[t]{2}{*}{$P$ value } \\
\hline & \multicolumn{2}{|l|}{$n^{\mathrm{a}}$} & \multicolumn{2}{|l|}{$n^{\mathrm{a}}$} & \\
\hline & 47 & $0.4(0-16.1)$ & 60 & $0.6(0-17.0)$ & 0.220 \\
\hline Male gender & 47 & $25(53 \%)$ & 60 & $39(65 \%)$ & 0.238 \\
\hline Advanced pediatric life support (APLS) & 47 & $25(53 \%)$ & 60 & $43(72 \%)$ & 0.068 \\
\hline Out-of-hospital arrest & 47 & $21(47 \%)$ & 60 & $18(30 \%)$ & 0.157 \\
\hline Bystander CPR & 47 & $46(98 \%)$ & 57 & $56(98 \%)$ & 1.00 \\
\hline Initial rhythm non-shockable & 36 & $31(86 \%)$ & 56 & $48(86 \%)$ & 1.00 \\
\hline \multicolumn{6}{|l|}{ Etiology } \\
\hline Cardiac & 47 & $16(34 \%)$ & 60 & $22(37 \%)$ & 0.840 \\
\hline Respiratory & 47 & $23(49 \%)$ & 60 & $35(58 \%)$ & 0.434 \\
\hline Other & 47 & $8(17 \%)$ & 60 & $3(5 \%)$ & 0.056 \\
\hline Pre-existing medical condition ${ }^{\mathrm{b}}$ & 47 & $26(55 \%)$ & 60 & $29(48 \%)$ & 0.560 \\
\hline Cardiac & 26 & $13(50 \%)$ & 29 & $17(59 \%)$ & 0.840 \\
\hline Respiratory & 26 & $10(39 \%)$ & 29 & $10(35 \%)$ & 0.434 \\
\hline Other & 26 & $3(12 \%)$ & 29 & $2(7 \%)$ & 0.056 \\
\hline Mild therapeutic hypothermia ${ }^{c}$ & 47 & $7(15 \%)$ & 60 & $15(25 \%)$ & 0.235 \\
\hline \multicolumn{6}{|l|}{ Socioeconomic status at follow-up ${ }^{\mathrm{d}}$} \\
\hline Level 1: "Low" & 47 & $4(9 \%)$ & 60 & $14(23 \%)$ & 0.066 \\
\hline Level 2: "Middle" & 47 & $21(45 \%)$ & 60 & $31(52 \%)$ & 0.560 \\
\hline Level 3: "High" & 47 & $22(47 \%)$ & 60 & $15(25 \%)$ & 0.024 \\
\hline Age at follow-up (years) & 47 & $8.7(2.4-18.3)$ & - & - & - \\
\hline
\end{tabular}

All data are presented as "number of subject $(\%)$ ", except age which is presented as "median (range)". Significant value ( $p<$ 0.05 ) in bold

$C P R$ cardiopulmonary resuscitation, ICU intensive care unit, $n$ number, - not available

${ }^{\text {a }}$ Number of subjects from which the variable was obtained

b Children with a pre-existing medical history which was the cause of the CA

${ }^{\mathrm{c}}$ Children treated with mild therapeutic hypothermia

(TEA-Ch: $Z=-1.999, p=0.046$ ), cognitive shifting and inhibition (Stroop: $Z=-2.050, p=0.040$ ) (Supplementary Table 2). Older age at time of CA and followup were associated with worse outcomes on language ( $\rho=-0.414, \quad p=0.008 ; \quad \rho=-0.408, \quad p=0.009)$. Older age at follow-up was also associated with worse outcomes on visual-motor integration $(\rho=-0.312$, $p=0.047)$. Children with a CA-related pre-existing medical condition scored worse on attentional switching than children without $(Z=-2.716, p=0.007)$. Children with BLS scored worse than children with APLS on the TMT part A $(Z=-2.522, p=0.012)$. Children without follow-up scored significantly worse on divided attention $(Z=-2.116, p=0.034)$ and TMT part B $(Z=-2.000$, $p=0.046)$ than children participating in the follow-up program. Predictors of outcome on the BRIEF questionnaires are shown in Supplementary Table 4.

\section{Discussion}

This is one of the first studies that has systematically examined the long-term neuropsychological outcomes in
${ }^{\mathrm{d}}$ SES for non-participants at time of follow-up was calculated on the basis of a combined status score of the Netherlands Institute for Social Research based on home address [24]. This score consisted of four variables: average income in neighborhood, percentage of people with low income, percentage of less educated people, and percentage of people not working. A status score of $0( \pm 1.16 \mathrm{SD})$ was classified as middle SES, a status score of $<-1.16$ was classified as low SES, and a status score of $>+1.16$ was classified as high SES

children surviving cardiac arrest (CA). As a result of the CA, $6 \%$ sustained such serious brain damage that they could not be tested. CA survivors scored significantly worse on intelligence. On neuropsychological tests, significantly worse scores were found on visual memory, significant better scores on verbal memory (recognition), and no differences on visual-motor integration, attention, verbal memory (RAVLT 1-5, delayed recall), and executive functioning. On questionnaires, parents reported better executive functioning, but teachers reported more problems in planning/organizing skills.

\section{Neuropsychological functioning \\ Intelligence tests}

Conform former research, lower scores were found on all intelligence scales [10, 11]. In general, intellectual outcome is highly dependent on the age at which brain injury was acquired. Acquired brain injury $(\mathrm{ABI})$ at a young age results in more diffuse deficits in cognitive functioning, rather than specific deficits [25]. This can 
Table 2 Overview of intelligence and neuropsychological outcome adjusted for participants' IQ

\begin{tabular}{|c|c|c|c|c|c|c|c|c|}
\hline & \multicolumn{4}{|c|}{ Cardiac arrest patients } & & \multicolumn{3}{|c|}{ Normative data } \\
\hline & $n$ & Mean & & SD & & Mean & SD & $P$ value \\
\hline \multicolumn{9}{|l|}{ Intelligence } \\
\hline Full scale $\mathrm{IQ}^{\mathrm{a}}$ & 41 & 87.3 & & 13.4 & & 100 & 15 & 0.002 \\
\hline Verbal $\mathrm{IQ}^{\mathrm{b}}$ & 39 & 92.7 & & 13.7 & & 100 & 15 & $<0.001$ \\
\hline Performance $\mathrm{IQ}^{\mathrm{b}}$ & 39 & 85.6 & & 12.7 & & 100 & 15 & $<0.001$ \\
\hline Processing speed index ${ }^{\mathrm{a}, \mathrm{c}}$ & 31 & 91.1 & & 15.6 & & 100 & 15 & 0.004 \\
\hline Verbal comprehension index ${ }^{\mathrm{d}}$ & 25 & 93.4 & & 14.7 & & 100 & 15 & 0.033 \\
\hline Perceptual organization index ${ }^{\mathrm{d}}$ & 25 & 83.8 & & 13.9 & & 100 & 15 & $<0.001$ \\
\hline Intelligence subtest: digit span & 25 & 8.0 & & 3.1 & & 10 & 3 & 0.009 \\
\hline \multicolumn{2}{|l|}{ Neuropsychological tests ${ }^{\mathrm{e}}$} & $n^{\mathrm{f}}$ & Mean & SD & Mean & SD & $P$ value & $P$ value adjusted for $\mathrm{IQ}^{\mathrm{e}}$ \\
\hline \multicolumn{2}{|c|}{ Peabody picture vocabulary test (PPVT) } & 40 & -0.12 & 1.2 & 0 & 1 & 0.451 & 0.002 \\
\hline \multicolumn{2}{|c|}{ Beery visual-motor Integration (Beery VMI) } & 41 & -0.85 & 0.9 & 0 & 1 & $<0.001$ & 0.841 \\
\hline \multicolumn{2}{|l|}{ Stroop color word test } & 23 & -1.14 & 2.4 & 0 & 1 & 0.059 & 0.692 \\
\hline \multicolumn{9}{|c|}{ Test of everyday attention for children (TEA-Ch) } \\
\hline \multicolumn{2}{|l|}{ Sky search time per target } & 22 & -0.76 & 1.1 & 0 & 1 & 0.004 & 0.235 \\
\hline \multicolumn{2}{|c|}{ Sky search attention score (selective attention) } & 23 & -0.96 & 1.3 & 0 & 1 & 0.003 & 0.646 \\
\hline \multicolumn{2}{|l|}{ Score! (sustained attention) } & 23 & -0.59 & 1.3 & 0 & 1 & 0.052 & 0.502 \\
\hline \multicolumn{2}{|c|}{ Creature counting accuracy (attentional switching) } & 23 & -0.29 & 1.0 & 0 & 1 & 0.173 & 0.010 \\
\hline \multicolumn{2}{|l|}{ Creature counting timing score } & 23 & -0.68 & 1.2 & 0 & 1 & 0.017 & 0.204 \\
\hline \multicolumn{2}{|c|}{ Sky search double task decrement (divided attention) } & 23 & -1.51 & 1.3 & 0 & 1 & $<0.001$ & 0.059 \\
\hline \multicolumn{9}{|c|}{ Rey complex figure test (ROCF) } \\
\hline \multicolumn{2}{|l|}{ ROCF copy } & 23 & -0.42 & 1.3 & 0 & 1 & 0.338 & 0.181 \\
\hline \multicolumn{2}{|l|}{ ROCF immediate recall } & 25 & -1.89 & 1.0 & 0 & 1 & $<0.001$ & $<0.001$ \\
\hline \multicolumn{2}{|l|}{ ROCF delayed recall } & 25 & -1.87 & 1.0 & 0 & 1 & $<0.001$ & $<0.001$ \\
\hline \multicolumn{2}{|l|}{ ROCF recognition } & 25 & -0.66 & 1.0 & 0 & 1 & $\mathbf{0 . 0 2 2}$ & 0.510 \\
\hline \multicolumn{9}{|c|}{ Rey's auditory verbal learning test (RAVLT) } \\
\hline \multicolumn{2}{|c|}{ RAVLT $1-5$} & 25 & -0.66 & 1.0 & 0 & 1 & 0.005 & 0.339 \\
\hline \multicolumn{2}{|l|}{ RAVLT delayed recall } & 25 & -0.79 & 1.2 & 0 & 1 & 0.003 & 0.716 \\
\hline \multicolumn{2}{|c|}{ RAVLT recognition } & 24 & -0.27 & 1.1 & 0 & 1 & 0.373 & 0.010 \\
\hline \multicolumn{9}{|c|}{ Trail-making test part A and B (TMT A/B) } \\
\hline \multicolumn{2}{|l|}{ TMT A } & 25 & -0.43 & 1.0 & 0 & 1 & 0.042 & 0.109 \\
\hline \multicolumn{2}{|l|}{ TMT B } & 25 & -0.65 & 1.0 & 0 & 1 & 0.003 & 0.158 \\
\hline
\end{tabular}

Significant values $(p<0.05)$ in bold

a Intelligence scores of different age-groups were combined for the total sample by combining scores on, respectively: (1) Wechsler Preschool and Primary Scale of Intelligence (WPPSI-III; $n=16$ ), (2) Wechsler Intelligence Scale for Children (WISC-III; $n=23$ ), and (3) Wechsler Adult Intelligence Scale (WAIS-IV; $n=2$ ). One child was too young to be tested with the WPPSI-III ( $<2.6$ years), and for one child the testing of intellectual functioning had to be stopped prematurely due to substantial attentional problem behavior, which made accurate testing of the intellectual functioning impossible

b Intelligence scores combined for the total group of (1) Wechsler Preschool and Primary Scale of Intelligence (WPPSI-III), and (2) Wechsler Intelligence Scale for Children (WISC-III). WAIS-IV does not include the PIQ and VIQ

be explained by the vulnerability theory, since children with ABI at young age have to learn new skills with impaired basal functions [26]. The most susceptible areas to ischemic injury within the brain are vascular end zones, hippocampus, insular cortex, and basal ganglia [27]. With an increasing severity of hypoxic ischemia, more extensive and global neocortical injury will occur and could lead to global cerebral atrophy, as shown in adults [27, 28]. Moreover, ABI at young age has longlasting effects on intelligence [29].
${ }^{c}$ Procession Speed Index is not available for children $<4,5$ years $(n=10)$, on the WPPSI-III

${ }^{d}$ Perceptual organization index and verbal comprehension index are not available on the WPPSI-III $(n=16)$

e All neuropsychological test were converted into $Z$ scores and compared with the $Z$ score ( -0.84 ) of the mean IQ of CA survivors, as significant difference in intelligence were found and developmental delay (lower IQ) worsens their abilities on neuropsychological tests

${ }^{\mathrm{f}}$ Numbers of patients differ for neuropsychological tests due to different age ranges and diversity in availability of normative data. The $n$ is the actual number of patients tested

\section{Neuropsychological tests}

Long-term neuropsychological functioning has mainly been assessed in subgroups of CA patients, i.e. congenital heart disease or drowned children $[10,11]$. Besides impairments in intelligence, impairments in verbal and/or visual memory, visual-perceptual-motor functioning, and executive functions were also found $[10,11]$.

A discrepancy between visual and verbal information processing is not only found on our results on the 


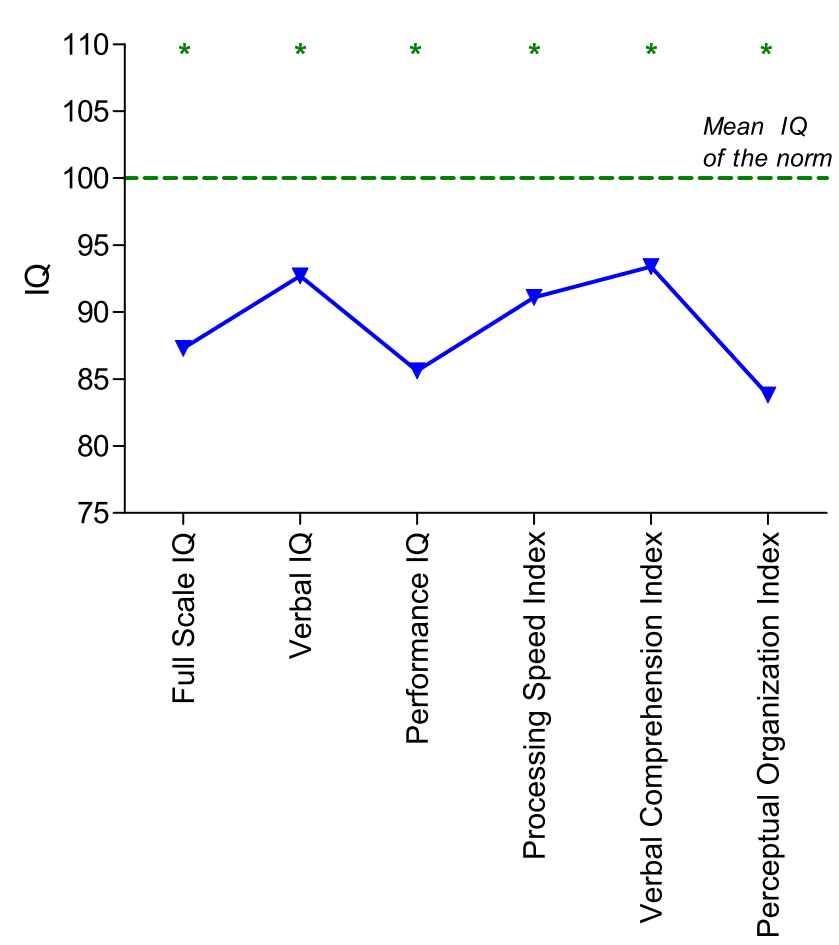

Fig. 2 Results on intelligent tests compared with normative data. * Significantly different from the norm



Fig. 3 Results on neuropsychological tests, adjusted for mean fullscale IQ of CA survivors. *Significantly different from the norm. **Significantly different from what would be expected based on the mean full-scale IQ of CA survivors intelligence profile but also on our memory results, as only visual memory problems (Rey) were found, not verbal memory problems (RAVLT). In addition, the PPVT and TEA-Ch attentional switching are both verbal tasks. Since the children's verbal functions are relatively good, this may result in an overestimation and better reported executive functioning by parents, as instructions by parents are mainly verbal. Academic achievement tasks at school are both visual-spatial and verbal orientated, which is reflected by the lower executive functioning reported by teachers. As these children have visual weaknesses and relatively intact verbal functioning, the visual-spatial deficits could be supported by verbal instructions at school, to improve their academic achievements.

Various pathological mechanisms may explain our findings on the neuropsychological tests. The hippocampus, playing an important role in memory, is sensitive to cerebral hypoperfusion. While neuronal injury is mostly observed within $3 \mathrm{~h}$ after ROSC, delayed neuronal death, especially in the hippocampus, can be present up to 48-72 h after ROSC [30].

Furthermore, the watershed areas in the brain are particularly vulnerable to effects of hypoperfusion and hypoxia resulting in cognitive deficits and prefrontal lesions [31]. Cognitive deficits could be explained by periventricular leukomalacia (white matter injury), which is believed to arise from several factors including ischemia to the watershed areas [5]. As the integrity of the white matter is correlated with full-scale IQ and performance IQ, and not with verbal IQ, white matter injury could be an important explanation for our findings in CA survivors [32]. Damage to the prefrontal region could result in various types of frontal syndromes, which manifest themselves in deficits in executive functions, information processing and attention. The relatively high scores on the BRIEF do not necessarily mean better functioning, but could be an expression of a dorsolateral prefrontal syndrome. This syndrome is characterized by lack of initiative, personality changes, blunted affect, or problems with executive functions such as working memory and planning. Children with a lack of initiative are more dependent on external stimulation; rapid emotional changes and high distractibility are less common. This would also explain the positive results on the teacher-reported inhibition scale. Unfortunately, no imaging was performed, which could have provided valuable information on the neuropsychological outcome and CArelated brain damage [33].

\section{Questionnaire}

Parents reported significantly better executive functions, particularly in behavior regulation, as compared to par- 
Table 3 Parent, teacher, and self-reported executive functioning

\begin{tabular}{|c|c|c|c|}
\hline BRIEF parents-report & $\begin{array}{l}\text { Patients } \\
\text { Mean (SD) } \\
n=31^{\mathrm{a}}\end{array}$ & $\begin{array}{l}\text { Norm } \\
\text { Mean (SD) } \\
n=770\end{array}$ & $P$ value \\
\hline $\begin{array}{l}\text { Behavioral regulation index } \\
\text { Inhibit } \\
\text { Shift } \\
\text { Emotional control } \\
\text { Metacognition index } \\
\text { Organization of materials } \\
\text { Monitor } \\
\text { Global executive composite }\end{array}$ & $\begin{array}{l}39.52(12.0) \\
13.81(4.3) \\
10.97(3.5) \\
14.74(5.2) \\
72.52(21.6) \\
10.68(3.9) \\
12.77(4.3) \\
112.03(31.4) \\
\end{array}$ & $\begin{array}{l}45.22(11.3) \\
15.78(4.5) \\
12.62(3.5) \\
16.79(5.0) \\
78.60(17.5) \\
12.14(3.3) \\
14.81(3.7) \\
124.13(26.0) \\
\end{array}$ & $\begin{array}{l}\mathbf{0 . 0 0 3} \\
\mathbf{0 . 0 0 3} \\
\mathbf{0 . 0 0 4} \\
\mathbf{0 . 0 1 6} \\
0.108 \\
\mathbf{0 . 0 3 1} \\
\mathbf{0 . 0 1 7} \\
\mathbf{0 . 0 2 4} \\
\end{array}$ \\
\hline BRIEF teacher-report & $n=15^{\mathrm{a}}$ & $n=778$ & $P$ value \\
\hline $\begin{array}{l}\text { Behavioral regulation index } \\
\text { Inhibit } \\
\text { Metacognition index } \\
\text { Plan/organize } \\
\text { Global executive composite }\end{array}$ & $\begin{aligned} & 39.73(12.9) \\
& 13.33(3.9) \\
& 75.27(23.8) \\
& 16.73(4.7) \\
& 115.00(34.7)\end{aligned}$ & $\begin{array}{c}42.89(13.3) \\
15.54(6.0) \\
70.00(21.0) \\
13.84(4.2) \\
112.88(31.6)\end{array}$ & $\begin{array}{l}0.099 \\
\mathbf{0 . 0 2 0} \\
0.589 \\
\mathbf{0 . 0 4 1} \\
0.910\end{array}$ \\
\hline BRIEF self-report & $n=8^{\mathrm{a}}$ & $n=379$ & $P$-value \\
\hline $\begin{array}{l}\text { Behavioral regulation index } \\
\text { Metacognition index } \\
\text { Global executive composite }\end{array}$ & $\begin{array}{r}48.25(8.9) \\
52.75(15.7) \\
101.00(22.5)\end{array}$ & $\begin{array}{r}52.02(11.2) \\
56.60(12.8) \\
108.62(21.8)\end{array}$ & $\begin{array}{l}0.207 \\
0.574 \\
0.327\end{array}$ \\
\hline
\end{tabular}

Only the index scores and composite scores, and subscales on BRIEF Behaviour rating inventory of executive function which significant differences were found when compared with ${ }^{a}$ The actual number of respondents to the questionnaire normative data, are presented. A complete overview of all results on the BRIEF is presented in Supplementary Table 3. Higher scores implicate worse executive functioning. Significant values $(p<$ 0.05 ) in bold

ents of healthy children. These results are in contrast to the negative outcomes in, e.g., patients with TBI or neonatal encephalopathy $[34,35]$. Teachers reported deficits in planning/organizing skills and only favorable scores on inhibition.

Parental results on questionnaires are not supported by test results on executive functioning; on the TMT and STROOP lower outcomes found compared to normative data. Possibly, the favorable scores were influenced by "response shift" [36]. Due to the CPR, and the often traumatic and emotional experiences related to the critical illness of their child, parents have expected a worse outcome and may be happy with their child's present functioning [37]. They therefore may overestimate the capacities of their child. Favorable outcome may also be explained by social desirability, or denial.

Furthermore, the BRIEF questionnaire may not measure executive functions to the extent that is commonly believed [38]. A recent study in critical cyanotic congenital heart disease also showed significant impairments on neuropsychological testing, but remarkably the scores on the BRIEF were average [39].

Noteworthy, executive functions are part of the higher cognitive functions. Increasing deficits may emerge later in childhood when these functions are expected to mature; this phenomenon is called "growing into deficits" [40].
Predictors of outcome

Univariable analyses were limited by the small number of patients, and therefore no strong conclusions can be drawn. However, there are some hypothesis-generating findings.

Overall, it is to be expected that males have a higher chance on worse neuropsychological functioning as to anatomical differences between the male and female brain. The right hemisphere of males is larger and contains more white matter than the right hemisphere of females. The impairments are found on visual-orientated tasks, which are functions more related to the right hemisphere. These results support the hypothesis of white matter injury.

In addition, older age at time of CA leads to more specific deficits, rather than global deficits, which could be explained by the vulnerability theory. Also, increasing deficits may emerge later in childhood when functions are expected to mature (growing into deficits phenomenon).

Further, our findings that children with a CA-related pre-existing medical condition scored worse on attentional switching than those without indicated that neuropsychological impairments can be related to the preexisting condition. For example, children with a congenital heart disease and children treated with ECMO, both without $\mathrm{CA}$, also have attentional problems $[5,7]$. 
Lastly, significantly better scores were found on divided attention and TMT part B in children participating in the follow-up program. Due to the multidisciplinary follow-up, children may have been referred to a professional (mental) healthcare provider in a more timely manner.

\section{Limitation}

First, this is a single center cohort study in a heterogeneous population. Second, since participants with a high SES are relatively overrepresented, our results may be too positive, since SES is an important predictor of outcome. Third, correction for multiple testing was not applied since this is an explorative and descriptive study. We did not want to miss any influences on long-term neuropsychological outcomes. Fourth, although we assessed the executive functions with the BRIEF questionnaire, the executive functions were not extensively tested with neuropsychological tests. Finally, some important variables are lacking, such as time to ROSC, severity of underlying illness, and treatment/course after ROSC during ICU admission.

\section{Conclusion}

Long-term neuropsychological testing of CA survivors showed significant weaknesses, but also relatively intact functioning. A structural neuropsychological follow-up screening is warranted, since cognitive deficits can be expected later in life ("grown into deficit"). Considering academic achievement, verbal support could improve these children's visual-spatial tasks.

Conflicts of interest The authors declare that they have no conflict of interest.

Open Access This article is distributed under the terms of the Creative Commons Attribution-NonCommercial 4.0 International License (http://creativecommons.org/licenses/by-nc/4.0/), which permits any noncommercial use, distribution, and reproduction in any medium, provided you give appropriate credit to the original author(s) and the source, provide a link to the Creative Commons license, and indicate if changes were made.

\section{References}

1. Topjian AA, Nadkarni VM, Berg RA (2009) Cardiopulmonary resuscitation in children. Curr Opin Crit Care 15:203-208

2. Lopez-Herce J, Del Castillo J, Matamoros M, Canadas S, RodriguezCalvo A, Cecchetti C, RodriguezNunez A, Alvarez AC, Iberoamerican Pediatric Cardiac Arrest Study Network R (2013) Factors associated with mortality in pediatric in-hospital cardiac arrest: a prospective multicenter multinational observational study. Intensive Care Med 39:309-318

3. Donoghue AJ, Nadkarni V, Berg RA, Osmond MH, Wells G, Nesbitt L, Stiell IG (2005) Out-of-hospital pediatric cardiac arrest: an epidemiologic review and assessment of current knowledge. Ann Emerg Med 46:512-522

4. Michiels EA, Dumas F, Quan L, Selby L, Copass M, Rea T (2013) Long-term outcomes following pediatric out-ofhospital cardiac arrest. Pediatr Crit Care Med 14:755-760

5. Wernovsky G (2006) Current insights regarding neurological and developmental abnormalities in children and young adults with complex congenital cardiac disease. Cardiol Young 16(Suppl 1):92-104
6. Vermunt LC, Buysse CM, Aarsen FK, Catsman-Berrevoets CE, Duivenvoorden HJ, Joosten KF, Hazelzet JA, Verhulst FC, Utens EM (2009) Long-term cognitive functioning in children and adolescents who survived septic shock caused by Neisseria meningitidis. Br J Clin Psychol 48:195-208

7. Madderom MJ, Reuser JJ, Utens EM, van Rosmalen J, Raets M, Govaert P, Steiner K, Gischler SJ, Tibboel D, van Heijst AF, Ijsselstijn H (2013)

Neurodevelopmental, educational and behavioral outcome at 8 years after neonatal ECMO: a nationwide multicenter study. Intensive Care Med 39:1584-1593

8. Maryniak A, Bielawska A, Walczak F, Szumowski L, Bieganowska K, Rekawek J, Paszke M, Szymaniak E, Knecht M (2008) Long-term cognitive outcome in teenage survivors of arrhythmic cardiac arrest. Resuscitation 77:46-50

9. Amicuzi I, Cappelli F, Stortini M, Cherubini S, Pierro MM (2005) Followup of neuropsychological function recovery in a 9-year-old girl with anoxic encephalopathy: a window on the brain re-organization processes. Brain Inj 19:371-388
10. Morris RD, Krawiecki NS, Wright JA, Walter LW (1993) Neuropsychological, academic, and adaptive functioning in children who survive in-hospital cardiac arrest and resuscitation. J Learn Disabil 26:46-51

11. Suominen PK, Sutinen N, Valle S, Olkkola KT, Lonnqvist T (2014) Neurocognitive long term follow-up study on drowned children. Resuscitation 85:1059-1064

12. Wechsler D (2012) Wechsler adult intelligence scale, 4th edn. Nederlandstalige bewerking. [Dutch version of the WAIS-IV]. Pearson, Amsterdam

13. Hendriksen J, Hurks P (2009) WPPSIIII NL. Wechsler preschool and primary scale of intelligence-3rd edn. Nederlandstalige bewerking. Afnameen scoringshandleiding. [Dutch version of the WPPSI-III]. Pearson, Amsterdam

14. Kort W, Schittekatte M, Dekker PH, Verhaeghe P, Compaan EL, Bosmans M, Vermeir G (2005) WISC-III NL Wechsler intelligence scale for children. Derde Editie NL. Handleiding en Verantwoording [Dutch version of the WISC-III]. Harcourt Test Publishers/Nederlands Instituut voor Psychologen, Amsterdam 
15. Dunn LM, Dunn LM (2005) Peabody picture vocabulary test-III-NL. Nederlandse versie door Liesbeth Schlichting. [Dutch version of the PPVT]. Harcourt, Amsterdam

16. Kok TB, Kingma A (2009) Herkenningsgeheugen bij kinderen [Dutch reference data for the RAVLT]. Tijdschrift voor Neuropsychologie 4:42-49

17. Schmand B, Houx P, de Koning I (2012) Normen 15-woordentest [Dutch reference data for the RAVLT]. sectie Neuropsychologie, Nederlands Instituut van Psychologen, Amsterdam

18. Rey A (1964) L'examen clinique en psychologie. Presses Universitaires de France, Paris

19. Beery KE, Beery NA (2004) The Beery-Buktenica developmental test of visual-motor integration, 5th edn. Pearson, Minneapolis

20. Manly T, Robertson IH, Anderson V, Nimmo-Smith I (1999) The test for everyday attention for children (TEACh). Nederlandse vertaling 2004. [Dutch version of the TEA-Ch]. Thames Valley Test, Bury St. Edmunds

21. Schmand B, Houx P, de Koning I (2005) Normen voor stroop kleurwoord tests, trail making test en story recall van de rivermead behavioral memory test [Dutch reference data for the Stroop, TMT]. Sectie

Neuropsychologie, Nederlands Centrum voor Psychologen, Amsterdam

22. Strauss E, Sherman EMS, Spreen O (2006) A compendium of neuropsychological tests : administration, norms, and commentary. Oxford University Press, New York

23. Smidts D, Huizinga M (2009) BRIEF : executieve functies gedragsvragenlijst [Dutch version of the BRIEF]. Hogrefe Uitgevers, Amsterdam

24. The Netherlands Institute for Social Research (Sociaal en Cultureel Planbureau) (2012) Rangorde naar sociale status van postcodegebieden in Nederland. http://www.scp.nl/. Accessed 6 Apr 2014
25. Middleton JA (2001) Brain injury in children and adolescents. Adv Psychiatr Treat 7:257-265

26. Taylor HG, Alden J (1997) Age-related differences in outcomes following childhood brain insults: an introduction and overview. J Int Neuropsychol Soc 3:555-567

27. Suominen PK, Vahatalo R (2012) Neurologic long term outcome after drowning in children. Scand J Trauma Resusc Emerg Med 20:55

28. Grubb NR, Fox KA, Smith K, Best J, Blane A, Ebmeier KP, Glabus MF, O'Carroll RE (2000) Memory impairment in out-of-hospital cardiac arrest survivors is associated with global reduction in brain volume, not focal hippocampal injury. Stroke 31:1509-1514

29. Anderson V, Godfrey C, Rosenfeld JV, Catroppa C (2012) Predictors of cognitive function and recovery 10 years after traumatic brain injury in young children. Pediatrics 129:e254e261

30. Harukuni I, Bhardwaj A (2006) Mechanisms of brain injury after global cerebral ischemia. Neurol Clin 24:1-21

31. Gonzalez FF, Miller SP (2006) Does perinatal asphyxia impair cognitive function without cerebral palsy? Arch Dis Child Fetal Neonatal Ed 91:F454F459

32. Chiang MC, Barysheva M, Shattuck DW, Lee AD, Madsen SK, Avedissian C, Klunder AD, Toga AW, McMahon KL, de Zubicaray GI, Wright MJ, Srivastava A, Balov N, Thompson PM (2009) Genetics of brain fiber architecture and intellectual performance. J Neurosci 29:2212-2224

33. Oualha M, Gatterre P, Boddaert N, Dupic L, De Saint Blanquat L, Hubert P, Lesage F, Desguerre I (2013) Early diffusion-weighted magnetic resonance imaging in children after cardiac arrest may provide valuable prognostic information on clinical outcome. Intensive Care Med 39:1306-1312
34. Sesma HW, Slomine BS, Ding R, McCarthy ML, Children's Health After Trauma Study G (2008) Executive functioning in the first year after pediatric traumatic brain injury. Pediatrics 121:e1686-e1695

35. Marlow N, Rose AS, Rands CE, Draper ES (2005) Neuropsychological and educational problems at school age associated with neonatal encephalopathy. Arch Dis Child Fetal Neonatal Ed 90:F380-F387

36. Opić, P (2013) Impact of congenital heart disease at adulthood. Erasmus University Rotterdam, Rotterdam. http://hdl.handle.net/1765/41382

37. Antonelli M, Bonten M, Chastre J, Citerio G, Conti G, Curtis JR, De Backer D, Hedenstierna G, Joannidis M, Macrae D, Mancebo J, Maggiore SM, Mebazaa A, Preiser JC, Rocco P, Timsit JF, Wernerman J, Zhang $\mathrm{H}$ (2012) Year in review in Intensive Care Medicine 2011: III. ARDS and ECMO, weaning, mechanical ventilation, noninvasive ventilation, pediatrics and miscellanea. Intensive Care Med 38:542-556

38. McAuley T, Chen S, Goos L, Schachar R, Crosbie J (2010) Is the behavior rating inventory of executive function more strongly associated with measures of impairment or executive function? J Int Neuropsychol Soc 16:495-505

39. Cassidy AR, White MT, DeMaso DR, Newburger JW, Bellinger DC (2015) Executive function in children and adolescents with critical cyanotic congenital heart disease. J Int Neuropsychol Soc 21(1):34-49

40. Aarsen FK, Paquier PF, Reddingius RE, Streng IC, Arts WF, Evera-Preesman M, Catsman-Berrevoets CE (2006) Functional outcome after low-grade astrocytoma treatment in childhood. Cancer 106:396-402 